linking basic pathological science with applied clinical situations. Such interactions are enhanced by the use of photography or still video imaging.

\section{Conclusions}

Historically, the medical profession has ensured the quality of medical care by controlling the credentials of medical practitioners. In recent years attention has turned towards the assessment of outcomes or performance measures. Although necropsy represents an opportunity to study outcomes, the non-random nature of necropsy populations, the failure to collect relevant data and the lack of quality assurance for necropsy examinations currently precludes any meaningful benefits. If this situation is to change then pathologists must first put their own house in order and introduce guidelines for necropsy practice.

ROGER D START Lecturer in Pathology SIMON S CROSS Senior Lecturer in Pathology
Department of Pathology,

Sheffield University Medical School,

Beech Hill Road,

Sheffield S10 2UL

e-mail:s.s.cross@sheffield.ac.uk

1 Robinson IR, Marley NJE. Which factors predict cases with unexpected clinical findings at necropsy? F Clin Pathol 1996;49:909-12.

2 Hutchins GM and the Autopsy Committee of the College of American Pathologists. Practice guidelines for autopsy pathology: autopsy performance. Arch Pathol Lab Med 1994;118:19-25.

3 Hutchins GM and the Autopsy Committee of the College of American Pathologists. Practice guidelines for autopsy pathology: autopsy reporting. Arch Pathol Lab Med 1995;119:123-30.

4 Powers JM and the Autopsy Committee of the College of American Pathologists. Practice guidelines for autopsy pathology: autopsy procedures for brain, spinal cord and neuromuscular system. Arch Pathol Lab Med 1995;119:777-83.

5 Cotton DWK, Cross SS. The hospital autopsy. Oxford: ButterworthHeinemann, 1993.

6 Royal College of Pathologists. Autopsy and audit. London: Royal College of Pathologists, 1991.

7 Royal College of Pathologists. Guidelines for post mortem reports. London: Royal College of Pathologists, 1993.

8 Young NA, Naryshkin S. An implementation plan for autopsy quality control and quality assurance. Arch Pathol Lab Med 1993;117:531-4.

\title{
Proliferative activity in invasive breast carcinoma
}

Determination of proliferative activity provides important diagnostic and prognostic information in many tumours, including invasive breast cancer. Histological grading of breast carcinoma (which includes mitotic count), is now not only widely accepted as providing robust prognostic information but also as showing acceptable reproducibility. However, if grading is not carried out diligently by histopathologists on well fixed samples, the prognostic information provided is likely to be of relatively poor quality and in such a setting a more objective system, and also a simple technique for the determination of the growth fraction of a tumour, has long been sought.

Thymidine and 5-bromodeoxyuridine labelling, S-phase fraction assessed by flow cytometry and determination of the proportion of the tumour showing immunostaining with the $\mathrm{Ki}-67$ antibody on frozen sections all have disadvantages. Disaggregation of tumour cells or access to fresh or frozen tissue may be needed. Large studies of patients with long term follow up have therefore been difficult to validate using these techniques. More recently, antibodies which can be used to determine the proliferation index of a tumour on paraffin wax sections have been described including MIB-1, Ki-S1 and anti-proliferating cell nuclear antigen (PCNA). The former recognises the $\mathrm{Ki}-67$ antigen, which is present in all cells active in the growth cycle-that is, not in $G_{0}$ phase, in routinely processed paraffin wax sections with the use of antigen retrieval ${ }^{1}$ and seems to be the most suitable of these antibodies. The technique is simple (although it may be affected by the $\mathrm{pH}$ of the buffering solution used) and correlates well with $\mathrm{Ki}-67$ immunoreactivity on frozen specimens, as described by Querzoli et al in this issue. ${ }^{2}$ A strong correlation between MIB-1 expression and histological grade has been described previously. ${ }^{34}$ There is also some evidence that MIB-1 expression may be relatively resistant to a delay in fixation of up to eight hours, ${ }^{5}$ whereas mitoses are significantly less robust and notoriously difficult to identify in poorly fixed tumours. Thus, MIB-1 evaluation may be valuable in the determination of the proliferation index in tumours which have not been fixed immediately and in which grading is therefore sub-optimal.

The MIB-1 labelling index shows strong correlations with other biological and histopathological features of invasive breast carcinomas, and also with clinical outcome. ${ }^{24}$ The results of Querzoli et al in this issue, assessing the proportion MIB-1 immunoreactivity by image analysis confirm that correlations with tumour size and survival are seen, but also a correlation with $\mathrm{p} 53$ and c-erbB-2 expression and inverse correlations with both oestrogen and progesterone receptor status. ${ }^{2}$ A correlation with lymph node stage (although using the TNM staging system) is more unexpected and has not been seen by other authors. ${ }^{34}$

The major benefit of determining the percentage area showing immunoreactivity by image analysis is the objectivity of the technique, but it should not be taken for granted that this ensures good intra- and inter-observer reproducibility. Poor reproducibility of the cell proliferation index using image analysis has been reported-for example, only $56 \%$ agreement in $\mathrm{Ki}-67$ immunostaining by three observers was seen by Makkink-Nombrado et al. ${ }^{6}$ These authors found that the poor reproducibility seemed to be related to a bias in the "random" field selection. In addition, although direct light microscopic visualisation ensures that only malignant cells are included in the proliferation index by image analysis, this necessitates accurate interpretation of tissue sections by fully trained staff to ensure only tumour tissue is included in the analysis. Despite these difficulties, previous small series have shown a good correlation $(r=0.77)$ between the image analysis determination and light microscopic estimate of the percentage nuclear immunostaining with MIB-1. ${ }^{7}$ Semiquantitative light microscopic assessment of MIB-1 immunoreactivity may be of use in examining proliferation in imperfectly fixed tumours

Whichever technique is selected for determination of the proliferation index of a tumour, it is imperative that strict criteria must be agreed and adhered to, whether in defining the characteristics of a mitotic figure or in ensuring the 
randomness of the fields to be included by image analysis. Only if the technique is robust, reproducible and cost effective will it be widely accepted; the use of image analysis to assess the proliferation index of a tumour objectively is attractive in principle but is both time consuming and, in comparison with routine grading, expensive. In centres where histological grading is not available it may, however, be a feasible alternative.

$S$ E PINDER

C W ELSTON

I O ELLIS

Department of Histopathology,

Nottingham City Hospital NHS Trust,

Nottingham NG5 $1 P B$

1 Cattoretti G, Becker MH, Key G, Duchrow M, Schluter C, Galle J, et al. Monoclonal antibodies against recombinant parts of the Ki-67 antigen
(MIB 1 and MIB 3) detect proliferating cells in microwave-processed formalin-fixed paraffin sections. $\mathcal{F}$ Pathol 1992;168:357-63.

2 Querzoli P, Albonico G, Ferretti S, Rinaldi R, Magri E, Indelli M, et al. MIB1 proliferative activity measured by image analysis in invasive breast cancer. $\mathcal{F}$ Clin Pathol 1996;49:926-30.

3 Ostrowski ML, Chakraborty S, Laucirica R, Brown RW, Greenberg SD. Quantitative image analysis of MIB-1 immunoreactivity: A comparison Quantitative image analysis of MIB-1 immunoreactivity: A comparison
with flow cytometric assessment of proliferative activity in invasive carcinoma of the breast. Anal Quant Cytol Histol 1995;17:15-24.

4 Pinder SE, Wencyk P, Sibbering DM, Bell JA, Elston CW, Nicholson R, et al. Assessment of the new proliferation marker MIB1 in breast carcinoma using image analysis: Associations with other prognostic factors and survival. Br f Cancer 1995;71:146-9.

5 Hendricks JB, Wilkinson EJ. Quality control considerations for Ki-67 detection and quantitation in paraffin-embedded tissue. $\mathcal{f}$ Cell Biochem 1994;56: tion and $105-10$.

6 Makkink-Nombrado SV, Baak JPA, Schuurmans L, Theeuwes JW, Van der Aa T. Quantitative immunohistochemistry using the CAS 200/486 image analysis system in invasive breast carcinoma: A reproducibility study. Anal Cell Pathol 1995;8:227-45.

7 Pinder SE, Wencyk PM, Naylor HE, Bell JA, Elston CW, Robertson JFR, et al. The assessment of multiple variables on breast carcinoma fine needle aspiration (FNA) cytology specimens: Method, preliminary results and prognostic associations. Cytopathology 1995;6:316-24. 